\title{
Fertility-sparing treatment in early endometrial cancer: current state and future strategies
}

\author{
Andreas Obermair, MD, FRANZCOG, CGO1', Eva Baxter, PhD', Donal J. Brennan, MD, PhD²,3, \\ Jessica N. McAlpine, MD ${ }^{4,5}$, Jennifer J. Mueller, $\mathrm{MD}^{6,7}$, Frédéric Amant, MD, PhD ${ }^{8,9}$, \\ Mignon D. J. M. van Gent, MD, PhD ${ }^{9}$, Robert L. Coleman, MD ${ }^{10}$, Shannon N. Westin, MD, MPH ${ }^{10}$, \\ Melinda S. Yates, PhD ${ }^{10}$, Camilla Krakstad, PhD ${ }^{11,12}$, Monika Janda, PhD ${ }^{13}$
}

\begin{abstract}
'Queensland Centre for Gynaecological Cancer Research, The University of Queensland, Brisbane, Australia; ${ }^{2}$ Department of Gynaecological Oncology, UCD School of Medicine, Catherine McAuley Research Centre, Mater Misericordiae University Hospital; ${ }^{3}$ Systems Biology Ireland, University College Dublin, Dublin, Ireland; ${ }^{4}$ Division of Gynecologic Oncology, Department of Gynecology and Obstetrics, The University of British Columbia; ${ }^{5} \mathrm{BC}$ Cancer Agency, Vancouver, Canada; ${ }^{6}$ Department of Surgery, Memorial Sloan Kettering Cancer Center; ${ }^{7}$ Department of Obstetrics \& Gynecology, Weill Cornell Medical College, New York, NY, USA; ${ }^{8}$ Department of Oncology, KU Leuven, Leuven, Belgium; ${ }^{9}$ Center for Gynecologic Oncology Amsterdam, AVLNKI and Amsterdam University Medical Center; ${ }^{10}$ Department of Gynecologic Oncology and Reproductive Medicine, The University of Texas M. D. Anderson Cancer Center, Houston, TX, USA; ${ }^{11}$ Centre for Cancer Biomarkers CCBIO, Department of Clinical Science, University of Bergen; ${ }^{12}$ Department of Obstetrics and Gynecology, Haukeland University Hospital, Bergen, Norway; ${ }^{13}$ Centre for Health Services Research, The University of Queensland, Brisbane, Australia
\end{abstract}

Endometrial cancer $(E C)$ is the fifth most common cancer in women worldwide. Global estimates show rising incidence rates in both developed and developing countries. Most women are diagnosed postmenopausal, but $14-25 \%$ of patients are premenopausal and $5 \%$ are under 40 years of age. Established risk factors include age and hyperestrogenic status associated with nulliparity, obesity, and metabolic syndrome. Standard treatment for EC, which involves total hysterectomy and bilateral salpingo-oophorectomy, has excellent survival outcomes, particularly for low-grade endometrioid tumors. However, it leads to permanent loss of fertility among women who wish to preserve their reproductive potential. With current trends of reproductive-age women delaying childbearing, rising EC incidence rates, and a growing epidemic of obesity, particularly in developed countries, research on conservative non-surgical treatment approaches remains a top priority. Fertility-sparing treatment predominantly involves the use of oral progestins and levonorgestrel-releasing intrauterine devices, which have been shown to be feasible and safe in women with early stage EC and minimal or no myometrial invasion. However, data on the efficacy and safety of conservative management strategies are primarily based on retrospective studies. Randomized clinical trials in younger women and high-risk obese patients are currently underway. Here, we have presented a comprehensive review of the current literature on conservative, fertility-sparing approaches, defining the optimal candidates and evaluating tumor characteristics, reproductive and oncologic outcomes, and ongoing clinical trials. We have also summarized current guidelines and recommendations based on the published literature.

Keywords: Endometrial cancer; Fertility preservation; Conservative treatment; Progestin

\section{Introduction}

Endometrial cancer (EC) is the fifth most common gynecological cancer in developed countries, with an estimated worldwide incidence of 382,069 new cases per year $[1,2]$. The highest age-standardized incidence rates in 2018 were estimated to be 19.1 and 22.2 per 100,000 women in North America and Europe, respectively [2,3], attributable to the greater overall prevalence of obesity and metabolic syndromes [4]. Although the age-standardized rates were
Received: 2019.09.15. Revised: 2020.03.16. Accepted: 2020.04.03. Corresponding author: Andreas Obermair, MD, FRANZCOG, CGO

Queensland Centre for Gynaecological Cancer Research, The University of Queensland, St Lucia, Brisbane QLD 4072, Australia E-mail: a.obermair@uq.edu.au http://orcid.org/0000-0003-2199-1117

Articles published in Obstet Gynecol Sci are open-access, distributed under the terms of the Creative Commons Attribution Non-Commercial License (http://creativecommons. org/licenses/by-nc/3.0/) which permits unrestricted non-commercial use, distribution, and reproduction in any medium, provided the original work is properly cited.

Copyright $\odot 2020$ Korean Society of Obstetrics and Gynecology 


\section{Obstetrics \& Gynecology Science}

Vol. 63, No. 4, 2020

the lowest in middle-income countries, such as South Africa, Japan, and Brazil, these countries had the most rapid rates of increase in the past 10 years, at $11.3 \%, 5.9 \%$, and $5 \%$ annually, respectively. Similar trends were observed for premenopausal women and an increased risk of EC over successive generations was more pronounced in some Asian countries, Costa Rica, and New Zealand [5].

Although EC is typically considered a postmenopausal cancer, $14 \%-25 \%$ of patients are premenopausal and $5 \%$ are younger than 40 years; majority of the patients tend to present with low-grade early stage tumors of the endometrioid subtype that are confined to the endometrium [6-8]. Historically, EC has been categorized into 2 clinicopathological types-type $1 \mathrm{EC}$, the estrogen-dependent endometrioid type associated with obesity that accounts for up to $85 \%$ of ECs, and type 2, the non-endometrioid subtypes that include serous, clear-cell, undifferentiated carcinomas and malignantmixed Mullerian tumors and are typically not associated with obesity $[9,10]$. Tumor grade and myometrial invasion increase with age, accounting in part for the considerably worse prognosis of older patients $[11,12]$.

Established risk factors for EC include exposure to exogenous estrogens or endogenous hyperestrogenic status associated with nulliparity, early age at menarche, late-onset menopause, age, and obesity [13]. Women with greater weight gain after 20 years of age had a 3-fold increased risk of EC of any subtype and a 6-fold increased risk of the endometrioid subtype [14]. A higher fasting insulin level has been linked to EC risk, regardless of the menopausal status [15]. It has also been causally linked to EC risk independently of body mass index (BMI) [16].

The survival outcomes following current standard surgical treatment for EC are good, ranging from $74 \%$ to $91 \%$, particularly for women diagnosed with low-grade endometrioid tumors without lymph node involvement [17]. A Danish nationwide survey of EC patients with stage I tumors reported a 5 - and 10-year disease-specific survival of $99 \%$ and $98 \%$, respectively [18]. Younger women of reproductive age have significantly better disease-specific survival than older women independent of other prognostic indicators [19]. However, medical comorbidities can negatively impact survival outcomes. Diabetes and obesity are negative predictors of allcause and disease-specific mortality, regardless of the tumor type, and the presence of more than 2 major comorbidities other than diabetes significantly predicts cancer-specific mor- tality [20]. Cardiovascular disease is also a frequent cause of death among women who survive EC beyond 5 years [21].

The standard treatment for EC involving total hysterectomy and bilateral salpingo-oophorectomy (THBSO) with or without lymphadenectomy is effective [22]. Fertility-sparing treatment approaches for patients who wish to preserve childbearing involve endocrine treatments with oral progestins, medroxyprogesterone acetate (MPA) or megestrol acetate (MA), or gonadotropin-releasing hormone $(G n R H)$. More recently, levonorgestrel-releasing intrauterine devices (LNG-IUDs) have been used. However, there are inherent risks involved in conservative approaches, including the risk of the treatment being ineffective, the risk of relapse, and missing a diagnosis of ovarian or lymph node involvement (advanced stage disease) or synchronous ovarian cancer.

From this point forward, the term "fertility preservation" will refer to the preservation of the uterus. The role of ovarian preservation as part of the surgical management of EC is outside the scope of this review.

Given the current trends of women of reproductive-age delaying child-bearing and the increasing incidence of EC amongst nulliparous women $[23,24]$, high-level evidence on alternatives to THBSO are urgently required. Generating evidence on conservative treatments for low-risk EC has become a top priority [25].

\section{Defining candidates for fertility-sparing treatment}

\section{Young women desiring childbearing capacity}

Women of child-bearing age with an EC diagnosis frequently have early-stage, low-grade disease $[7,19,26]$ and although the standard treatment of THBSO is effective, they should be considered for non-surgical fertility-sparing treatment. The risks include missing occult lymph nodes or ovarian metastases. One possible solution could be a surgical exploration (including surgical node assessment) prior to fertility-sparing treatment. Rigorous follow-up is imperative. Estimates of age at first birth in the US show that 1 of 12 first births in 2006 were to women aged 35 and older, compared to 1 of 100 in 1970 [27].

\section{Women with significant medical co-morbidities}

For elderly women, substituting major surgery with effective 


\section{Obstetrics \& Gynecology Science}

Andreas Obermair, et al. Fertility-sparing for endometrial cancer

conservative alternatives may prevent major surgical complications. Patients with multiple medical comorbidities have a significantly higher risk of intra- and post-operative complications, including a prolonged hospital stay $[28,29]$. THBSO performed by laparoscopy in patients with early-stage EC was associated with less blood loss and pain, faster recovery, and a shorter hospital stay [30]. A recent meta-analysis of both the LACE [31] and the LAP2 [32] trials reported comparable survival outcomes for patients who had minimally invasive and those who had open surgery for EC [33]. Our group found that older patients with multiple pre-existing comorbidities, increased complexity of surgical procedures, higher American Society of Anesthesiologists (ASA) scores $\geq 2$ (the ASA scoring system classifies patients' preoperative physiological status and operative risk), and high BMI were independent predictors of any adverse event [34]. A prediction model that quantifies the risks of adverse events in patients undergoing surgical procedures for EC has also been outlined [35].

\section{Obese women in whom surgery is technically infeasible}

Perioperative risks and length of hospital stay are higher in obese women [35]. The rate of conversion from laparoscopy to laparotomy increases with higher BMI, with $57 \%$ of patients with $\mathrm{BMI} \geq 40 \mathrm{~kg} / \mathrm{m}^{2}$ requiring conversion [32]. Adverse events significantly increase healthcare costs [36]. The efficacy of treatment alternatives that are safe and less invasive needs to be addressed in this growing population of patients with obesity and EC, and the feMMe trial currently underway aims to evaluate fertility-sparing non-surgical treatment options in obese patients [37].

\section{Tumor characteristics}

Traditionally, the most suitable candidates for fertility-sparing treatment of EC have been patients with grade 1 tumors of the endometrioid subtype, with or without superficial invasion into the myometrium. These patients are more likely to present with estrogen- and progesterone-receptor positive tumors and progestin treatment results in encouraging outcomes. Patients with poorly differentiated tumors and deeply invasive disease (>50\%) are considered ineligible for fertility-sparing treatment by most investigators. Some guidelines even suggest that any myometrial invasion should be considered a contraindication to fertility preservation
[38]. Leitao et al. [39] compared grade 1 tumors diagnosed preoperatively with dilatation and curettage $(D \& C)$ or pipelle biopsy and found that significantly fewer tumors diagnosed by $D \& C$ were upgraded in the final hysterectomy specimen than those diagnosed by pipelle biopsy $(8.7 \%$ vs. $17.4 \%$; $P=0.007)$. Given reported disparities between pathologists in differentiating between complex atypical endometrial hyperplasia and grade 1 EC $[40,41]$, the accuracy of the final histological diagnosis for fertility-sparing treatment may be improved by a pathological review.

Patients with low-risk pathological features can expect a 5 -year overall survival rate ranging from $80 \%$ to $90 \%$. The accuracy of various methods to assess myometrial invasion have been widely reported in the literature. A meta-analysis of 9 studies found that both dynamic contrast-enhanced and diffusion-weighted magnetic resonance imaging (MRI) had high diagnostic accuracy in detecting deep myometrial invasion ( $86 \%$ pooled sensitivity for both methods) in women undergoing preoperative staging [42]. An earlier study suggested a high negative predictive value for deep myometrial invasion [43]. The implementation of both MRI and transvaginal ultrasonography (TVUS) appears to be highly effective in assessing myometrial invasion $[44,45]$. Similarly, comparisons of computed tomography, TVUS and MRI showed similar performance overall, but significantly better assessment of myometrial invasion with contrast-enhanced MRI [46]. TVUS performed by experts specializing in gynecological oncology had diagnostic accuracy comparable to MRI and greater inter-observer reproducibility for evaluating deep myometrial and cervical stromal invasion than that performed by general gynecologists $[45,47]$.

\section{Synchronous or metastatic ovarian cancer}

The reported rate of synchronous ovarian cancer in women with EC varies from $5 \%$ to $29 \%[26,48,49]$. Although EC patients aged $\leq 45$ years are 5 times more likely to have synchronous ovarian tumors than women aged $>45$ years, nulliparity and not age is an independent risk factor for synchronous ovarian cancer [26]. A large multi-center analysis by the Korean Society of Gynecologic Oncology found that while the incidence of synchronous ovarian cancer in young women with EC was quite low (4.5\%), synchronous ovarian cancer was not identified in women with low-risk EC [50]. A retrospective chart review of women aged $24-45$ years found that $88 \%$ of coexisting ovarian tumors identified at 


\section{Obstetrics \& Gynecology Science}

Vol. 63, No. 4, 2020

hysterectomy were synchronous primaries and 69\% occurred in women with grade $1 \mathrm{EC}$ [51]. There is evidence from the Surveillance, Epidemiology, and End Results database that the overall rate of synchronous ovarian cancer in EC patients has declined in the past 2 decades, but that rates peak between 29 and 47 years of age, followed by a significant decline [52].

Synchronous endometrial and ovarian carcinomas are seemingly independent co-occurrences of tumors at both the ovary and endometrium and are seen in 5\% of EC patients and $10 \%$ of ovarian cancer patients. Two groups have demonstrated a clonal relationship between each site $[53,54]$, disproving the concurrent theory of independent development of both tumors and suggesting that these cancers arise at one anatomic location and undergo restricted metastasis ("pseudometastases") to the second site. Failure to recognize a synchronous endometrial and ovarian carcinoma could allow the ovarian mass to progress and further metastasize, thereby changing a surgically curable disease into one requiring adjuvant chemotherapy with or without radiation, with an increased risk of recurrence and death from disease $[55,56]$.

\section{Family cancer history and genetic syndromes}

Patients presenting with EC at a young age may have a genetic etiology. The risks associated with family history of EC have been well documented in meta-analyses and population-based studies $[57,58]$ and may encompass a range of factors including shared environmental and lifestyle choices that may be influenced by genetic predisposition. The lifetime risk of EC in women with Lynch syndrome is estimated to be $40 \%$ to $60 \%$ and is primarily associated with germline mutations in one of the mismatch repair genes (MMR), MLH1, MSH2, MSH6, or PMS2 [59]. Analysis of a large series of Lynch families showed that the cumulative risk of EC by 70 years of age was substantially higher among MLH1 mutation carriers (54\%), but the risks did not exceed $2 \%$ in women under age 40 [60]. Population-based studies show that MMR defects underlie $<5 \%$ of EC at the population level, and the risk depends on which MMR gene is disrupted [61]. Current National Comprehensive Cancer Network (USA) guidelines for hereditary cancers recommend that all women with EC undergo genetic testing for MMR mutations, particularly women under 50 years of age and those from Lynch families [62]. Germline loss-of-function variants in the tu- mor suppressor gene PTEN have also been associated with increased risk of EC [63]. A comprehensive review of the evidence for genes implicated in hereditary EC and the available commercial testing panels have been presented in detail elsewhere [64].

At an increasing number of gynecological cancer centers, all patients diagnosed with EC are evaluated for Lynch syndrome by immunohistochemical staining of tumor histopathology specimens for MLH1, MSH2, PMS2, and MSH6 proteins, which are surrogate markers for Lynch syndrome. A diagnosis of Lynch syndrome and the associated risks for EC and ovarian cancer might impact a patient's decision regarding conservative, fertility-sparing treatment for EC.

\section{Fertility-sparing management}

\section{Hormonal therapy}

Fertility-sparing management of EC typically involves the use of the oral progestins MPA or MA, or more recently the LNG-IUD. The effectiveness of oral progestins remains unproven through randomized controlled clinical trials and the optimal dose and duration of progestin use have not been established. Current recommendations are MPA at a dose of 400-600 mg/day or MA at a dose of 160-320 mg/day for a minimum of 6 months, with follow-up assessment of treatment response using D\&C and imaging $[38,65]$. The LNGIUD releases $52 \mathrm{mg}$ of intrauterine progestin at a consistent rate for up to 5 years but declines thereafter.

Progestin use in women undergoing fertility-sparing treatment for atypical hyperplasia and EC have consistently shown good overall response rates (76-81\%) [66-68]. MA has been linked to higher remission probabilities compared to MPA and other hormonal treatments [66], which may be due to the relatively higher bioavailability of MA compared to MPA following oral administration [69]. A study of Korean women aged $\leq 40$ years with grade 1 endometrioid EC treated with daily oral MPA or MA had similar rates of complete response (77.7\%) after a median follow-up of 66 months; however, MPA was associated with a lower risk of recurrence compared to $M A$ and $B M I \geq 25 \mathrm{~kg} / \mathrm{m}^{2}$ was a significant factor in failure to achieve a complete response [70]. Weight changes during treatment with progestin therapy were also shown to have a minimal effect on response rates, and pre-treatment and post-treatment $\mathrm{BMI} \geq 25 \mathrm{~kg} / \mathrm{m}^{2}$ were significantly associ- 


\section{Obstetrics \& Gynecology Science}

Andreas Obermair, et al. Fertility-sparing for endometrial cancer

ated with a higher rate of recurrence, highlighting the importance of maintaining normal BMI during progestin treatment [71]. Obese patients are hyperestrogenic and suppressing the production of endogenous estrogen may be an effective alternative. A recent pilot study of a GnRH agonist combined with an aromatase inhibitor in fertility-sparing treatment of 6 obese women with grade $1 \mathrm{EC}$ reported a complete response in all women at 3-6 months, and a pregnancy and live birth rate of $50 \%$ and $75 \%$ respectively [72]. A prospective observation study of LNG-IUD for 1 year plus a GnRH analogue for 6 months in patients aged $<40$ years with stage $1 A$ EC showed results comparable to studies using MPA and MA, with a complete remission rate of $57 \%$ and a recurrence rate of $25 \%$ [73]. Although most studies report no significant toxicity among patients treated with high-dose oral progestins, adverse effects include thrombophlebitis, pulmonary emboli, weight gain, hypertension, and headaches, which may lead to low patient compliance $[40,74,75]$.

The LNG-IUD circumvents the issues with patient noncompliance that accompany oral medication as well as the possible side-effects associated with high-dose oral progestins. A recent meta-analysis of 5 randomized controlled trials comparing the LNG-IUD to oral cyclic MPA treatment found that although regression rates for both were similar overall, regression rates were higher for non-atypical endometrial hyperplasia and mixed (atypical and non-atypical) endometrial hyperplasia therapy among non-obese women [76]. A prospective multi-center study to determine the efficacy of the LNG-IUD in combination with oral MPA at $500 \mathrm{mg} /$ day in early-stage EC patients aged $<40$ years has been undertaken by the Korean Gynecologic Oncologic Group [77]. Several other randomized controlled trials are currently underway to evaluate the efficacy of LNG-IUDs with or without oral progestins or metformin in younger women with low-grade EC (Table 1).

\section{Hysteroscopic tumor resection}

Hysteroscopy as part of conservative management is controversial. Proponents claim it allows a more targeted removal of the primary site of disease plus adjacent margins and myometrium and permits a more accurate assessment of tumor characteristics through adequate biopsy sampling. Others find it challenging to distinguish the cancer tissue from surrounding hyperplasia. Studies reporting outcomes related to the use of hysteroscopy in conservative manage- ment are limited to case studies and case series. Alonso et al. [23] reviewed studies published between 1975 and 2014 of EC patients aged $<40$ years treated with initial hysteroscopic resection followed by hormone therapy for fertility-sparing and found that the complete response rate for patients with stage $1 \mathrm{~A}$ grade $1 \mathrm{EC}$ was $88.9 \%$. Pregnancy rates in these studies among those who attempted conception, including through assisted reproductive technology (ART), ranged from $25 \%$ to $66 \%$, suggesting the potential for superior outcomes compared to hormone treatment alone. Recent studies have confirmed these findings, reporting complete response rates in women with stage 1A EC of $89 \%$ to $97 \%$ following hysteroscopic fertility-sparing treatment, and pregnancy rates of over $45 \%$ among women who attempted conception $[78,79]$. Concerns have been raised about possible negative consequences of hysteroscopy due to EC cells spreading into the peritoneal cavity and the likelihood of adverse pregnancy outcomes due to mechanical damage to the basal layer of the endometrium causing Asherman's syndrome and a risk of placenta accreta [80].

\section{Follow-up examinations}

It is critically important that patients who are considered for fertility-sparing treatment understand and accept the need for close follow-up and endometrial sampling to evaluate the response to treatment. The optimal duration of progestin treatment that would achieve a complete response has been established, but there is little evidence to suggest added benefit beyond 6 months. A meta-analysis of 24 studies involving 370 patients undergoing fertility-sparing treatment showed that the remission probability after 6 months of treatment was $72 \%$ compared to $78 \%$ after 12 months of treatment, suggesting marginal benefit beyond 6 months [66]. There is variation across gynecologic oncology societies regarding the frequency of follow-up and method of endometrial sampling, primarily because of differences in treatment protocols, but current recommendations are for histological evaluation at 3-6 months by endometrial biopsy through D\&C rather than aspiration biopsy $[65,81]$. Establishment of a complete response, defined as no evidence of progressive disease, is a good indicator that pregnancy may be pursued, with ongoing close follow-up for early detection of successful pregnancy or signs of recurrence. Patients who partially respond to treatment at 6 months may be advised to continue progestin treatment for an additional 3-6 months, and non-responders 


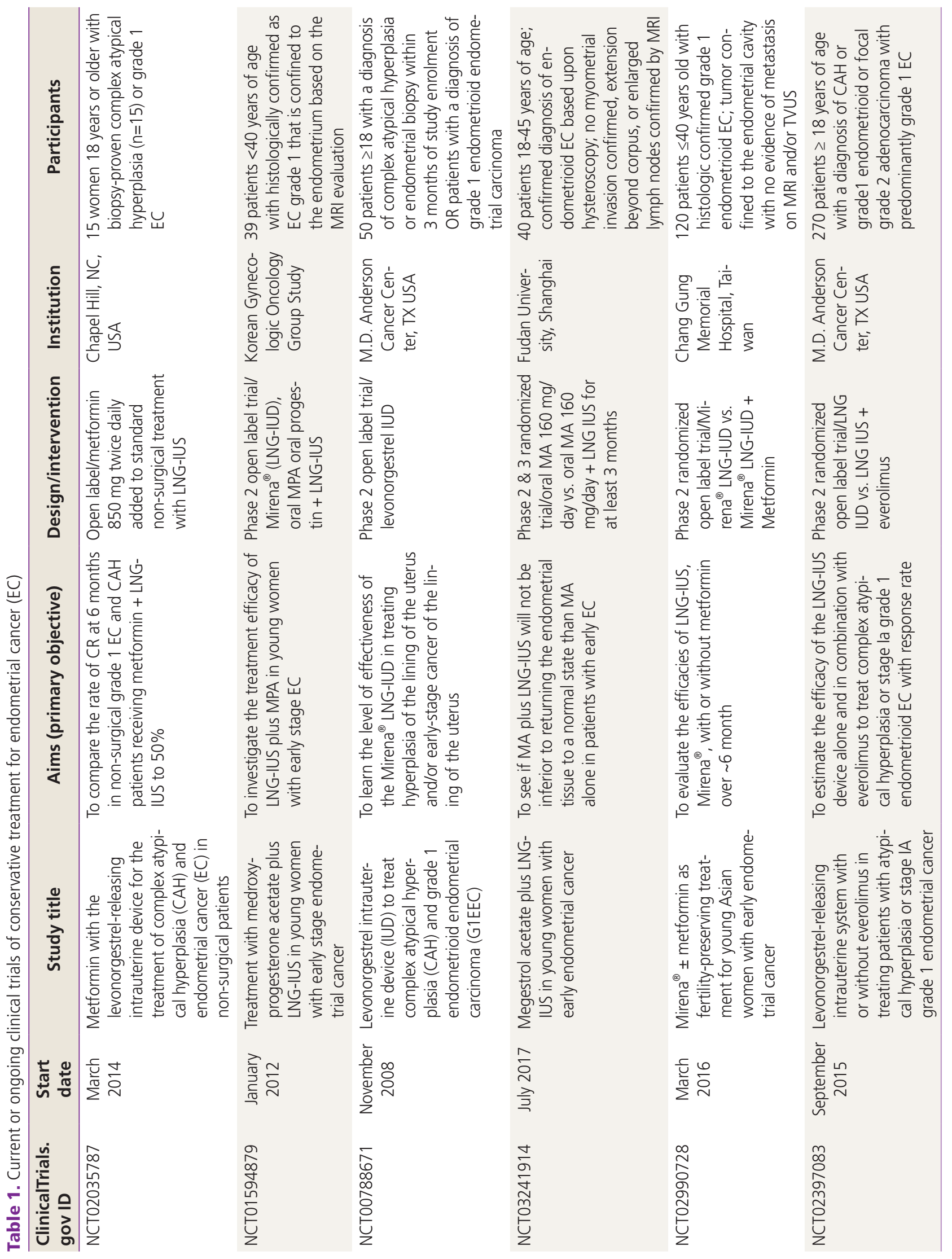




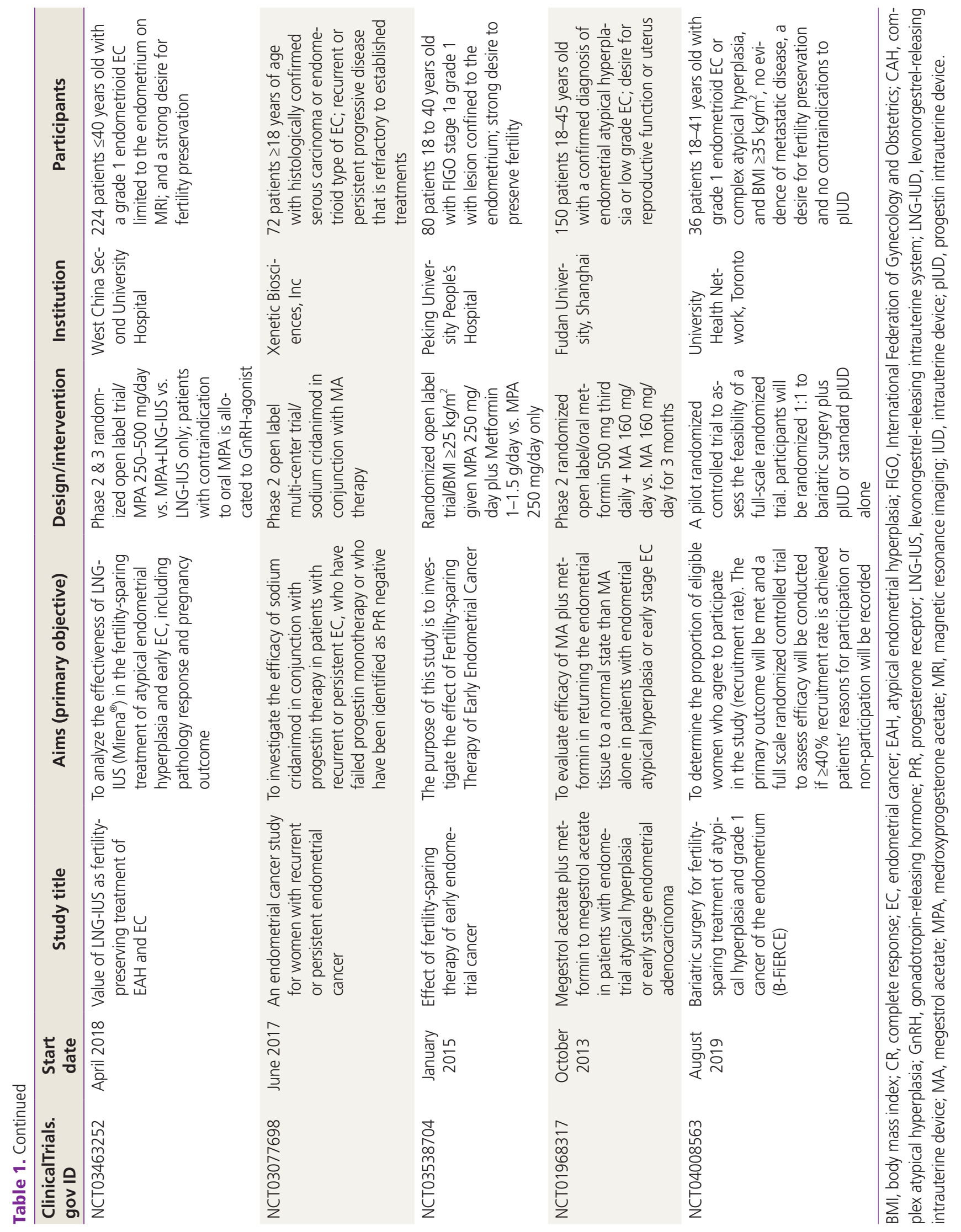




\section{Obstetrics \& Gynecology Science}

Vol. 63, No. 4, 2020

at the 6-month follow-up with persistent disease confirmed by $D \& C$ should be counselled to undergo hysterectomy.

\section{Reproductive and oncologic outcomes}

Reproductive outcomes in EC patients who undergo fertilitysparing treatment are promising, although estimates vary according to patient characteristics and whether ART is used. A multi-center study of 141 Korean women aged $<40$ years who were diagnosed with grade 1 endometrioid EC and treated with oral progestins showed that $73 \%$ of women who attempted conception, including a subset receiving fertility drugs, were successful, and that $66 \%$ had at least 1 live birth. Although the incidence of infertility in this cohort was higher than in the general population, those who received fertility treatments had similar 5-year disease-free survival rates compared to those who did not, and women who had at least 1 pregnancy had better disease-free survival rates compared to those who did not [82]. A more recent analysis of 118 Korean women with stage 1A grade 1-2 endometrioid EC treated with MPA and the LNG-IUD reported a live birth rate of $67 \%$ among those who tried to become pregnant and had full-term pregnancies. In this cohort, the median disease-free survival was 26 months among those who became pregnant, compared to 12 months among those who did not, suggesting that successful pregnancy may improve disease-free survival [83]. The benefits of pregnancy on recurrence were also documented by Ichinose et al. [84], who found that all women in their study receiving ART had a live birth and a lower risk of recurrence compared to those who did not achieve pregnancy. However, obesity negatively impacts pregnancy rates and lowers the probability of long-term treatment success among women receiving fertility-sparing treatment $[85,86]$. This remains an ongoing challenge to conservative management of EC, and highquality data from randomized controlled trials are needed to successfully address this issue [87].

\section{Future strategies and recommendations}

The incidence of EC is rising, particularly in countries with rapid socioeconomic growth. Increases in obesity in these countries and a global decline in reproductive rates will increase the need for fertility-sparing approaches to treatment [5]. EC is among the 10 most frequent cancers in Latin American and Caribbean countries (7.7 per 100,000 women) and may reflect changes in reproductive patterns in conjunction with rising rates of obesity in these countries [88]. In high-income countries, the proportion of women with high BMI $\left(\geq 25 \mathrm{~kg} / \mathrm{m}^{2}\right)$ rose at a faster rate than the global average between 1980 and 2013, with the exception of Japan, where despite lower rates of obesity, EC rates continued to rise, highlighting the involvement of other risk factors [5]. The global prevalence of type 2 diabetes, which is known to be associated with EC and correlates with high $\mathrm{BMI}$, has risen from $4.7 \%$ in 1980 to $9.0 \%$ in 2014 in adults aged $>18$ years [89]. Further discussion is warranted on the optimal approach to follow-up, including the frequency of endometrial re-evaluation in patients desiring fertility-sparing treatment, without compromising a patient's quality of life or increasing the risks associated with recurrence or survival.

Overall, mortality associated with conservative treatment of EC is low, and women aged $<45$ years with low-grade EC and minimal myometrial invasion who are treated with progestins seem to have good clinical outcomes comparable to those receiving primary hysterectomy [90]. However, there are reports in the published literature of fatalities following pregnancy in patients treated conservatively for well differentiated and non-invasive EC [91,92]. The importance of proper informed consent and strict follow-up procedures for patients opting for fertility-sparing treatment of EC cannot be overemphasized. Additional factors such as synchronous or metastatic ovarian cancer, or cancers associated with genetic predisposition need to be factored into current mortality estimates. Patients requesting fertility-sparing treatment should undergo testing for Lynch syndrome and be counselled prior to undertaking treatment. Additionally, patients with prior conditions that predispose to infertility, including obesity, polycystic ovarian syndrome, and anovulation, should be encouraged to seek ART for conception as soon as a complete response is achieved.

Feasibility studies for weight loss approaches with a view to improving EC treatment outcomes are critical to reducing the burden of this disease on healthcare resources. Significant reductions in excess body weight and improvements in biomarkers for insulin resistance and reproductive hormones among obese women undergoing bariatric surgery have been reported [93]. Bariatric surgery was shown to signifi- 


\section{Obstetrics \& Gynecology Science}

Andreas Obermair, et al. Fertility-sparing for endometrial cancer

cantly reduce the risk of EC among obese women [94]. These studies show promise for improving treatment in obese women, but further studies are necessary to determine the range of benefits on general health and the chance of fertility subsequent to fertility-sparing treatment for $\mathrm{EC}$.

The importance of progesterone receptor status has been discussed with regard to predicting treatment response. While the Gynecologic Oncology Branch of the Chinese Medical Association requires progesterone receptor status in patients undergoing fertility-sparing treatment, the European Society for Medical Oncology (ESMO) does not currently recommend routine testing because patients who test negative for progesterone status still respond to treatment, although their chance of a response is significantly lower [65]. The inclusion of immunohistochemical markers [95] and serum levels of cancer antigen CA125 [96] to predict response to treatment will require further studies. Risk classification of tumors in a fertility-sparing setting using molecular markers for p53 and MMR abnormalities has been trialed with promising results [97]. Endometrial biomarkers to predict resistance to therapy would prove beneficial and are currently being evaluated (NCT00788671). The feMME trial (ANZGOG NCT01686126) is a randomized clinical trial that investigates the effectiveness of LNG-IUD in women with early stage EC and a $\mathrm{BMI}>30 \mathrm{~kg} / \mathrm{m}^{2}$. It is a 3-arm randomized multicenter phase 2 study of LNG-IUD \pm metformin \pm weight loss intervention in 165 women [37]. Metformin is the most widely used anti-diabetic drug, and there is evidence from in vitro studies to suggest that it also has anti-cancer properties [98]. Results are expected to become available in 2020. Additionally, 4 Chinese studies are currently evaluating fertility-sparing treatments for early-stage EC: MPA $250 \mathrm{mg} /$ day \pm metformin 1-1.5 g/day (NCT03538704); MPA 250-500 mg/day vs MPA + LNG-IUD vs LNG-IUD (NCT03463252); oral MA 160 mg/ day \pm LNG-IUD (NCT03241914); and MA 160 mg/day \pm metformin (NCT01968317). A Taiwanese study is also currently evaluating LNG-IUD \pm metformin in young Asian women under the age of 40 years with early stage EC (NCT02990728), and the Korean Gynecologic Oncology Group is evaluating LNG-IUD + MPA in young women with grade 1 EC confined to the endometrium (NCT01594879). With the exception of a Korean study, which recently published a 6-month update [99], these and other trials outlined in Table 1 have not been published at the time of writing this review.

\section{Guidelines and recommendations}

Comprehensive evidence-based guidelines and recommendations for EC management were developed by the ESMO, the European Society of Gynaecological Oncology, and the European Society for Radiotherapy \& Oncology and published in 2015 [38]. The following summarizes their current recommendations for fertility-sparing treatment, including an update published in 2017 [100]:

- Conservative management should be considered in selected patients with grade $1 \mathrm{EC}$ or premalignant disease; patients must be referred to specialized centers, undergo histological diagnosis using D\&C with or without hysteroscopy, and have their diagnosis confirmed by a specialist gynecopathologist (Table 2). Overt myometrial invasion and adnexal involvement should be excluded

Table 2. Optimal candidates for non-surgical fertility-sparing treatment

\section{Terms of candidates}

1. Young women of child-bearing age (preferably women under age 40) diagnosed with EC

2. Definitive diagnosis of grade 1 tumor of the endometrioid subytpe with or without superficial invasion into the myometrium

3. Well differentiated tumors with $\leq 50 \%$ myometrial invasion assessesd by TVUS or MRI where TVUS is insufficient to assess

4. No evidence of synchronous or metachronous ovarian tumors evaluated by MRI or TVUS

5. No family history or hereditary cancer syndromes as evidenced by mutation testing primarily for Lynch Syndrome by immunohistochemical staining of tumor specimens for MMR proteins

6. No contraindications for hormonal treatment

7. Patients with comorbidities that preclude them from surgical treatment

8. Full acceptance and understanding that fertility-sparing treatment is not standard, carries a risk of recurrence, and requires close follow-up

EC, endometrial cancer; TVUS, transvaginal ultrasonography; MRI, magnetic resonance imaging; MMR, mismatch repair genes. 


\section{Obstetrics \& Gynecology Science}

Vol. 63, No. 4, 2020

using pelvic MRI or expert TVUS.

- Current recommendations for fertility-sparing therapy involve the use of oral progestins, MPA (400-600 mg/ day), MA (160-320 mg/day), or the LNG-IUD and assessment of patient responses by $D \& C$, hysteroscopy, and imaging at 6 months. Minor variations of fertility-sparing treatment by other gynecologic oncology societies are primarily in regards to follow-up biopsy; the Japan Society of Gynecologic Oncology recommends endometrial biopsy at 3 months following progestin treatment [101], and the Korean Society of Gynecologic Oncology recommends endometrial biopsy at 3-6 month for fertilitysparing treatment of grade 1 endometrioid tumors confined to the endometrium [102]. In addition, the Gynecologic Oncology Branch of the Chinese Medical Association requires patients to be under the age of 40 and progesterone-receptor positive to be considered for fertility-sparing therapy [103].

- Patients who wish to conceive following a complete response should be advised to pursue pregnancy earlier and consider ART to improve success rates. Those not ready to conceive immediately should be offered lowdose progestin or the LNG-IUD. After completion of childbearing, THBSO should be considered, although preservation of the ovaries would depend on age and genetic risk factors.

- Patients should be apprised of the pros and cons of fertility-sparing treatment and that there are inherent risks associated with this approach, including the likelihood of future hysterectomy if there is disease recurrence. They should also be willing to accept close follow-up during and after treatment at least bi-annually, which may include $D \& C$ and imaging to evaluate recurrence.

\section{Conclusion}

There is consensus across various leading gynecologic oncology societies that fertility-sparing treatment of EC must be considered a research priority. Research to estimate the effectiveness of fertility-sparing treatment of EC is underway. Research is also required to understand the information needs of patients considering fertility-sparing treatment of EC. Finally, further research is urgently required to determine the predictors of response to hormonal treatment.

\section{Acknowledgements}

The authors thank Dr Sharon Johnatty of SugarApple Communications for providing medical writing support, which was funded by the Queensland Centre for Gynecological Cancer, in accordance with Good Publication Practice (GPP3) guidelines (https://www.ismpp.org/gpp3). All authors critically reviewed the manuscript, and all authors approved the final submitted version.

\section{Conflict of interest}

No potential conflict of interest relevant to this article was reported.

\section{Ethical approval}

The study is not applicable to Institutional Review Board.

\section{Patient consent}

There is no need for patient consent in this review article.

\section{References}

1. Bray F, Ferlay J, Soerjomataram I, Siegel RL, Torre LA, Jemal A. Global cancer statistics 2018: GLOBOCAN estimates of incidence and mortality worldwide for 36 cancers in 185 countries. CA Cancer J Clin 2018;68:394-424.

2. Ferlay J, Colombet M, Soerjomataram I, Dyba T, Randi $\mathrm{G}$, Bettio $\mathrm{M}$, et al. Cancer incidence and mortality patterns in Europe: estimates for 40 countries and 25 major cancers in 2018. Eur J Cancer 2018;103:356-87.

3. Siegel RL, Miller KD, Jemal A. Cancer statistics, 2018. CA Cancer J Clin 2018;68:7-30.

4. Trabert B, Wentzensen N, Felix AS, Yang HP, Sherman ME, Brinton LA. Metabolic syndrome and risk of endometrial cancer in the united states: a study in the SEER-medicare linked database. Cancer Epidemiol Biomarkers Prev 2015;24:261-7. 


\section{Obstetrics \& Gynecology Science}

Andreas Obermair, et al. Fertility-sparing for endometrial cancer

5. Lortet-Tieulent J, Ferlay J, Bray F, Jemal A. International patterns and trends in endometrial cancer incidence, 1978-2013. J Natl Cancer Inst 2018;110:354-61.

6. Ota T, Yoshida M, Kimura M, Kinoshita K. Clinicopathologic study of uterine endometrial carcinoma in young women aged 40 years and younger. Int J Gynecol Cancer 2005;15:657-62.

7. Duska LR, Garrett A, Rueda BR, Haas J, Chang Y, Fuller AF. Endometrial cancer in women 40 years old or younger. Gynecol Oncol 2001;83:388-93.

8. Siegel RL, Miller KD, Jemal A. Cancer statistics, 2019. CA Cancer J Clin 2019;69:7-34.

9. Bokhman JV. Two pathogenetic types of endometrial carcinoma. Gynecol Oncol 1983;15:10-7.

10. Setiawan VW, Yang HP, Pike MC, McCann SE, Yu H, Xiang $Y B$, et al. Type I and II endometrial cancers: have they different risk factors? J Clin Oncol 2013;31:260718.

11. Creasman WT, Odicino F, Maisonneuve P, Quinn MA, Beller $U$, Benedet JL, et al. Carcinoma of the corpus uteri. FIGO 26th annual report on the results of treatment in gynecological cancer. Int J Gynaecol Obstet 2006;95 Suppl 1:S105-43.

12. Amant $F$, Moerman $P$, Neven $P$, Timmerman $D$, Van Limbergen $\mathrm{E}$, Vergote I. Endometrial cancer. Lancet 2005;366:491-505.

13. Webb PM. Environmental (nongenetic) factors in gynecological cancers: update and future perspectives. Future Oncol 2015;11:295-307.

14. Nagle CM, Marquart L, Bain CJ, O'Brien S, Lahmann $\mathrm{PH}$, Quinn $\mathrm{M}$, et al. Impact of weight change and weight cycling on risk of different subtypes of endometrial cancer. Eur J Cancer 2013;49:2717-26.

15. Hernandez AV, Pasupuleti V, Benites-Zapata VA, Thota P, Deshpande A, Perez-Lopez FR. Insulin resistance and endometrial cancer risk: a systematic review and metaanalysis. Eur J Cancer 2015;51:2747-58.

16. Nead KT, Sharp SJ, Thompson DJ, Painter JN, Savage DB, Semple RK, et al. Evidence of a causal association between insulinemia and endometrial cancer: a mendelian randomization analysis. J Natl Cancer Inst 2015;107:djv178.

17. Morice P, Leary A, Creutzberg C, Abu-Rustum N, Darai E. Endometrial cancer. Lancet 2016;387:1094-108.

18. Lajer H, Elnegaard S, Christensen RD, Ortoft G, Schle- dermann DE, Mogensen O. Survival after stage IA endometrial cancer; can follow-up be altered? A prospective nationwide Danish survey. Acta Obstet Gynecol Scand 2012;91:976-82.

19. Lee NK, Cheung MK, Shin JY, Husain A, Teng NN, Berek JS, et al. Prognostic factors for uterine cancer in reproductive-aged women. Obstet Gynecol 2007;109:655-62.

20. Nagle CM, Crosbie EJ, Brand A, Obermair A, Oehler MK, Quinn $M$, et al. The association between diabetes, comorbidities, body mass index and all-cause and cause-specific mortality among women with endometrial cancer. Gynecol Oncol 2018;150:99-105.

21. Ward KK, Shah NR, Saenz CC, McHale MT, Alvarez EA, Plaxe SC. Cardiovascular disease is the leading cause of death among endometrial cancer patients. Gynecol Oncol 2012;126:176-9.

22. American Cancer Society. Surgery for endometrial cancer [Internet]. Atlanta (GA): American Cancer Society; c2017 [cited 2019 Jul 3]. Available from: https://www. cancer.org/cancer/endometrial-cancer/treating/surgery. html.

23. Alonso S, Castellanos T, Lapuente F, Chiva L. Hysteroscopic surgery for conservative management in endometrial cancer: a review of the literature. Ecancermedicalscience 2015;9:505.

24. Navarria I, Usel M, Rapiti E, Neyroud-Caspar I, Pelte MF, Bouchardy C, et al. Young patients with endometrial cancer: how many could be eligible for fertilitysparing treatment? Gynecol Oncol 2009;114:448-51.

25. Creutzberg CL, Kitchener HC, Birrer MJ, Landoni F, Lu $\mathrm{KH}$, Powell M, et al. Gynecologic Cancer InterGroup ( $\mathrm{GCIG}$ ) endometrial cancer clinical trials planning meeting: taking endometrial cancer trials into the translational era. Int J Gynecol Cancer 2013;23:1528-34.

26. Evans-Metcalf ER, Brooks SE, Reale FR, Baker SP. Profile of women 45 years of age and younger with endometrial cancer. Obstet Gynecol 1998;91:349-54.

27. Matthews TJ, Hamilton BE. Delayed childbearing: more women are having their first child later in life. NCHS Data Brief 2009:1-8.

28. Gunderson CC, Java J, Moore KN, Walker JL. The impact of obesity on surgical staging, complications, and survival with uterine cancer: a Gynecologic Oncology Group LAP2 ancillary data study. Gynecol Oncol 


\section{Obstetrics \& Gynecology Science}

Vol. 63, No. 4, 2020

2014;133:23-7.

29. Obermair A, Brennan DJ, Baxter E, Armes JE, Gebski V, Janda M. Surgical safety and personal costs in morbidly obese, multimorbid patients diagnosed with early-stage endometrial cancer having a hysterectomy. Gynecol Oncol Res Pract 2016;3:1.

30. Mourits MJ, Bijen CB, Arts HJ, ter Brugge HG, van der Sijde R, Paulsen $L$, et al. Safety of laparoscopy versus laparotomy in early-stage endometrial cancer: a randomised trial. Lancet Oncol 2010;11:763-71.

31. Janda M, Gebski V, Davies LC, Forder P, Brand A, Hogg $R$, et al. Effect of total laparoscopic hysterectomy vs total abdominal hysterectomy on disease-free survival among women with stage I endometrial cancer: a randomized clinical trial. JAMA 2017;317:1224-33.

32. Walker JL, Piedmonte MR, Spirtos NM, Eisenkop SM, Schlaerth JB, Mannel RS, et al. Laparoscopy compared with laparotomy for comprehensive surgical staging of uterine cancer: Gynecologic Oncology Group Study LAP2. J Clin Oncol 2009;27:5331-6.

33. Asher R, Obermair A, Janda M, Gebski V. Disease-free and survival outcomes for total laparoscopic hysterectomy compared with total abdominal hysterectomy in early-stage endometrial carcinoma: a meta-analysis. Int J Gynecol Cancer 2018;28:529-38.

34. Kondalsamy-Chennakesavan $S$, Bouman C, De Jong $S$, Sanday K, Nicklin J, Land R, et al. Clinical audit in gynecological cancer surgery: development of a risk scoring system to predict adverse events. Gynecol Oncol 2009;115:329-33.

35. Kondalsamy-Chennakesavan S, Janda M, Gebski V, Baker J, Brand A, Hogg R, et al. Risk factors to predict the incidence of surgical adverse events following open or laparoscopic surgery for apparent early stage endometrial cancer: results from a randomised controlled trial. Eur J Cancer 2012;48:2155-62.

36. Kondalsamy-Chennakesavan S, Gordon LG, Sanday K, Bouman C, De Jong S, Nicklin J, et al. Hospital costs associated with adverse events in gynecological oncology. Gynecol Oncol 2011;121:70-5.

37. Hawkes AL, Quinn M, Gebski V, Armes J, Brennan D, Janda $\mathrm{M}$, et al. Improving treatment for obese women with early stage cancer of the uterus: rationale and design of the levonorgestrel intrauterine device \pm metformin \pm weight loss in endometrial cancer (feMME) trial. Contemp Clin Trials 2014;39:14-21.

38. Colombo N, Creutzberg C, Amant F, Bosse T, González-Martín A, Ledermann J, et al. ESMO-ESGOESTRO consensus conference on endometrial cancer: diagnosis, treatment and follow-up. Ann Oncol 2016;27:16-41.

39. Leitao MM Jr, Kehoe S, Barakat RR, Alektiar K, Gattoc LP, Rabbitt $C$, et al. Comparison of D\&C and office endometrial biopsy accuracy in patients with FIGO grade 1 endometrial adenocarcinoma. Gynecol Oncol 2009;113:105-8.

40. Kaku T, Yoshikawa H, Tsuda H, Sakamoto A, Fukunaga $M$, Kuwabara $Y$, et al. Conservative therapy for adenocarcinoma and atypical endometrial hyperplasia of the endometrium in young women: central pathologic review and treatment outcome. Cancer Lett 2001;167:39-48.

41. Zaino RJ, Kauderer J, Trimble CL, Silverberg SG, Curtin JP, Lim PC, et al. Reproducibility of the diagnosis of atypical endometrial hyperplasia: a Gynecologic Oncology Group study. Cancer 2006;106:804-11.

42. Andreano A, Rechichi G, Rebora P, Sironi S, Valsecchi MG, Galimberti S. MR diffusion imaging for preoperative staging of myometrial invasion in patients with endometrial cancer: a systematic review and metaanalysis. Eur Radiol 2014;24:1327-38.

43. Wu LM, Xu JR, Gu HY, Hua J, Haacke EM, Hu J. Predictive value of T2-weighted imaging and contrast-enhanced MR imaging in assessing myometrial invasion in endometrial cancer: a pooled analysis of prospective studies. Eur Radiol 2013;23:435-49.

44. Rodríguez-Trujillo A, Martínez-Serrano MJ, MartínezRomán S, Martí C, Buñesch L, Nicolau C, et al. Preoperative assessment of myometrial invasion in endometrial cancer by 3D ultrasound and diffusion-weighted magnetic resonance imaging: a comparative study. Int J Gynecol Cancer 2016;26:1105-10.

45. Savelli L, Ceccarini M, Ludovisi M, Fruscella E, De laco PA, Salizzoni E, et al. Preoperative local staging of endometrial cancer: transvaginal sonography vs. magnetic resonance imaging. Ultrasound Obstet Gynecol 2008;31:560-6.

46. Kinkel K, Kaji Y, Yu KK, Segal MR, Lu Y, Powell CB, et al. Radiologic staging in patients with endometrial cancer: a meta-analysis. Radiology 1999;212:711-8. 


\section{Obstetrics \& Gynecology Science}

Andreas Obermair, et al. Fertility-sparing for endometrial cancer

47. Eriksson LS, Lindqvist PG, Flöter Rådestad A, Dueholm M, Fischerova $D$, Franchi $D$, et al. Transvaginal ultrasound assessment of myometrial and cervical stromal invasion in women with endometrial cancer: interobserver reproducibility among ultrasound experts and gynecologists. Ultrasound Obstet Gynecol 2015;45:476-82.

48. Gallos ID, Yap J, Rajkhowa M, Luesley DM, Coomarasamy A, Gupta JK. Regression, relapse, and live birth rates with fertility-sparing therapy for endometrial cancer and atypical complex endometrial hyperplasia: a systematic review and metaanalysis. Am J Obstet Gynecol 2012;207:266.e1-266.e12.

49. Gitsch G, Hanzal E, Jensen D, Hacker NF. Endometrial cancer in premenopausal women 45 years and younger. Obstet Gynecol 1995;85:504-8.

50. Song T, Seong SJ, Bae DS, Suh DH, Kim DY, Lee KH, et al. Synchronous primary cancers of the endometrium and ovary in young women: a Korean Gynecologic Oncology Group Study. Gynecol Oncol 2013;131:624-8.

51. Walsh C, Holschneider C, Hoang Y, Tieu K, Karlan $B$, Cass I. Coexisting ovarian malignancy in young women with endometrial cancer. Obstet Gynecol 2005;106:693-9.

52. Matsuo K, Machida H, Blake EA, Holman LL, Rimel BJ, Roman LD, et al. Trends and outcomes of women with synchronous endometrial and ovarian cancer. Oncotarget 2018;9:28757-71.

53. Anglesio MS, Wang YK, Maassen M, Horlings HM, Bashashati A, Senz J, et al. Synchronous endometrial and ovarian carcinomas: evidence of clonality. J Natl Cancer Inst 2016;108:djv428.

54. Schultheis AM, Ng CK, De Filippo MR, Piscuoglio S, Macedo GS, Gatius $S$, et al. Massively parallel sequencing-based clonality analysis of synchronous endometrioid endometrial and ovarian carcinomas. J Natl Cancer Inst 2016;108:djv427.

55. Li J, Zhu Q, Yang B, Ning C, Liu X, Luo X, et al. Risk factors for ovarian involvement in young and premenopausal endometrioid endometrial cancer patients. Eur J Obstet Gynecol Reprod Biol 2018;222:151-4.

56. Soliman PT, Slomovitz BM, Broaddus RR, Sun CC, Oh $J C$, Eifel PJ, et al. Synchronous primary cancers of the endometrium and ovary: a single institution review of 84 cases. Gynecol Oncol 2004;94:456-62.
57. Win AK, Reece JC, Ryan S. Family history and risk of endometrial cancer: a systematic review and metaanalysis. Obstet Gynecol 2015;125:89-98.

58. Johnatty SE, Tan YY, Buchanan DD, Bowman M, Walters RJ, Obermair $A$, et al. Family history of cancer predicts endometrial cancer risk independently of Lynch syndrome: implications for genetic counselling. Gynecol Oncol 2017;147:381-7.

59. Sehgal R, Sheahan K, O'Connell PR, Hanly AM, Martin ST, Winter DC. Lynch syndrome: an updated review. Genes (Basel) 2014;5:497-507.

60. Bonadona V, Bonaïti B, Olschwang S, Grandjouan S, Huiart $L$, Longy $M$, et al. Cancer risks associated with germline mutations in $\mathrm{MLH1}$, MSH2, and MSH6 genes in Lynch syndrome. JAMA 2011;305:2304-10.

61. Buchanan DD, Tan YY, Walsh MD, Clendenning M, Metcalf AM, Ferguson K, et al. Reply to J. Moline et al. J Clin Oncol 2014;32:2278-9.

62. National Comprehensive Cancer Network. NCCN guidelines for patients: uterine neoplasms. Ver 1 [Internet]. Plymouth Meeting (PA): National Comprehensive Cancer Network; c2019 [cited 2019 Jul 29]. Available from: https://www.nccn.org/patients/guidelines/uterine/.

63. Tan MH, Mester JL, Ngeow J, Rybicki LA, Orloff MS, Eng C. Lifetime cancer risks in individuals with germline PTEN mutations. Clin Cancer Res 2012;18:400-7.

64. Spurdle AB, Bowman MA, Shamsani J, Kirk J. Endometrial cancer gene panels: clinical diagnostic vs research germline DNA testing. Mod Pathol 2017;30:1048-68.

65. Rodolakis A, Biliatis I, Morice P, Reed N, Mangler M, Kesic $V$, et al. European Society of Gynecological Oncology task force for fertility preservation: clinical recommendations for fertility-sparing management in young endometrial cancer patients. Int J Gynecol Cancer 2015;25:1258-65.

66. Koskas M, Uzan J, Luton D, Rouzier R, Daraï E. Prognostic factors of oncologic and reproductive outcomes in fertility-sparing management of endometrial atypical hyperplasia and adenocarcinoma: systematic review and meta-analysis. Fertil Steril 2014;101:785-94.

67. Gunderson CC, Fader AN, Carson KA, Bristow RE. Oncologic and reproductive outcomes with progestin therapy in women with endometrial hyperplasia and grade 1 adenocarcinoma: a systematic review. Gynecol 


\section{Obstetrics \& Gynecology Science}

Vol. 63, No. 4, 2020

Oncol 2012;125:477-82.

68. Ramirez PT, Frumovitz M, Bodurka DC, Sun CC, Levenback $C$. Hormonal therapy for the management of grade 1 endometrial adenocarcinoma: a literature review. Gynecol Oncol 2004;95:133-8.

69. Adlercreutz H, Eriksen PB, Christensen MS. Plasma concentrations of megestrol acetate and medroxyprogesterone acetate after single oral administration to healthy subjects. J Pharm Biomed Anal 1983;1:15362.

70. Park JY, Kim DY, Kim JH, Kim YM, Kim KR, Kim YT, et al. Long-term oncologic outcomes after fertilitysparing management using oral progestin for young women with endometrial cancer (KGOG 2002). Eur J Cancer 2013;49:868-74.

71. Park JY, Seong SJ, Kim TJ, Kim JW, Bae DS, Nam JH. Significance of body weight change during fertilitysparing progestin therapy in young women with early endometrial cancer. Gynecol Oncol 2017;146:39-43.

72. Zhang Z, Huang H, Feng F, Wang J, Cheng N. A pilot study of gonadotropin-releasing hormone agonist combined with aromatase inhibitor as fertility-sparing treatment in obese patients with endometrial cancer. J Gynecol Oncol 2019;30:e61.

73. Minig L, Franchi D, Boveri S, Casadio C, Bocciolone $L$, Sideri M. Progestin intrauterine device and GnRH analogue for uterus-sparing treatment of endometrial precancers and well-differentiated early endometrial carcinoma in young women. Ann Oncol 2011;22:643-9.

74. Thigpen JT, Brady MF, Alvarez RD, Adelson MD, Homesley HD, Manetta A, et al. Oral medroxyprogesterone acetate in the treatment of advanced or recurrent endometrial carcinoma: a dose-response study by the Gynecologic Oncology Group. J Clin Oncol 1999;17:1736-44.

75. VAN Heertum K, Liu J. Differential effects of progestogens used for menopausal hormone therapy. Clin Obstet Gynecol 2018;61:454-62.

76. Yuk JS, Song JY, Lee JH, Park WI, Ahn HS, Kim HJ. Levonorgestrel-releasing intrauterine systems versus oral cyclic medroxyprogesterone acetate in endometrial hyperplasia therapy: a meta-analysis. Ann Surg Oncol 2017;24:1322-9.

77. Kim MK, Seong SJ, Lee TS, Kim JW, Nam BH, Hong $\mathrm{SR}$, et al. Treatment with medroxyprogesterone ac- etate plus levonorgestrel-releasing intrauterine system for early-stage endometrial cancer in young women: single-arm, prospective multicenter study: Korean gynecologic oncology group study (KGOG2009). Jpn J Clin Oncol 2012:42:1215-8.

78. Yang B, Xu Y, Zhu Q, Xie L, Shan W, Ning C, et al. Treatment efficiency of comprehensive hysteroscopic evaluation and lesion resection combined with progestin therapy in young women with endometrial atypical hyperplasia and endometrial cancer. Gynecol Oncol 2019;153:55-62.

79. Falcone F, Laurelli G, Losito S, Di Napoli M, Granata $V$, Greggi S. Fertility preserving treatment with hysteroscopic resection followed by progestin therapy in young women with early endometrial cancer. J Gynecol Oncol 2017;28:e2.

80. Park JY. Hysteroscopy in fertility-sparing management for early endometrial cancer: a double-edged sword. J Gynecol Oncol 2017;28:e16.

81. Kim MK, Seong SJ, Song T, Kim ML, Yoon BS, Jun HS, et al. Comparison of dilatation \& curettage and endometrial aspiration biopsy accuracy in patients treated with high-dose oral progestin plus levonorgestrel intrauterine system for early-stage endometrial cancer. Gynecol Oncol 2013;130:470-3.

82. Park JY, Seong SJ, Kim TJ, Kim JW, Kim SM, Bae DS, et al. Pregnancy outcomes after fertility-sparing management in young women with early endometrial cancer. Obstet Gynecol 2013;121:136-42.

83. Chae SH, Shim SH, Lee SJ, Lee JY, Kim SN, Kang SB. Pregnancy and oncologic outcomes after fertilitysparing management for early stage endometrioid endometrial cancer. Int J Gynecol Cancer 2019;29:77-85.

84. Ichinose M, Fujimoto A, Osuga $Y$, Minaguchi T, Kawana $K$, Yano $T$, et al. The influence of infertility treatment on the prognosis of endometrial cancer and atypical complex endometrial hyperplasia. Int J Gynecol Cancer 2013;23:288-93.

85. Gonthier C, Walker F, Luton D, Yazbeck C, Madelenat $\mathrm{P}$, Koskas M. Impact of obesity on the results of fertility-sparing management for atypical hyperplasia and grade 1 endometrial cancer. Gynecol Oncol 2014;133:33-7.

86. Chen M, Jin Y, Li Y, Bi Y, Shan Y, Pan L. Oncologic and reproductive outcomes after fertility-sparing manage- 


\section{Obstetrics \& Gynecology Science}

Andreas Obermair, et al. Fertility-sparing for endometrial cancer

ment with oral progestin for women with complex endometrial hyperplasia and endometrial cancer. Int J Gynaecol Obstet 2016;132:34-8.

87. Janda M, McGrath S, Obermair A. Challenges and controversies in the conservative management of uterine and ovarian cancer. Best Pract Res Clin Obstet Gynaecol 2019;55:93-108.

88. WHO International Agency for Research on Cancer. Population fact sheet: Latin American and the Caribbean 2018 [Internet]. Lyon: WHO International Agency for Research on Cancer; c2018 [cited 2019 Aug 6]. Available from: http://gco.iarc.fr/today/data/factsheets/ populations/904-latin-america-and-the-caribbean-factsheets.pdf.

89. World Health Organization. Global status report on noncommunicable diseases 2014 [Internet]. Geneva: World Health Organization; c2014 [cited 2019 Jul 29]. Available from: https://www.who.int/nmh/publications/ ncd-status-report-2014/en/.

90. Greenwald ZR, Huang LN, Wissing MD, Franco EL, Gotlieb WH. Does hormonal therapy for fertility preservation affect the survival of young women with early-stage endometrial cancer? Cancer 2017;123:154554.

91. Kothari R, Seamon L, Cohn D, Fowler J, O'Malley DM. Stage IV endometrial cancer after failed conservative management: a case report. Gynecol Oncol 2008;111:579-82.

92. Ferrandina G, Zannoni GF, Gallotta V, Foti E, Mancuso $\mathrm{S}$, Scambia G. Progression of conservatively treated endometrial carcinoma after full term pregnancy: a case report. Gynecol Oncol 2005;99:215-7.

93. MacKintosh ML, Derbyshire AE, McVey RJ, Bolton J, Nickkho-Amiry $M$, Higgins $C L$, et al. The impact of obesity and bariatric surgery on circulating and tissue biomarkers of endometrial cancer risk. Int J Cancer 2019;144:641-50.

94. Anveden $\AA$, Taube M, Peltonen M, Jacobson P, Andersson-Assarsson JC, Sjöholm K, et al. Long-term incidence of female-specific cancer after bariatric surgery or usual care in the Swedish obese subjects study. Gynecol Oncol 2017;145:224-9.

95. Weinberger V, Bednarikova M, Hausnerova J, Ovesna
P, Vinklerova P, Minar L, et al. a novel approach to preoperative risk stratification in endometrial cancer: the added value of immunohistochemical markers. Front Oncol 2019;9:265.

96. Reijnen C, IntHout J, Massuger LF, Strobbe F, KüstersVandevelde HV, Haldorsen IS, et al. Diagnostic accuracy of clinical biomarkers for preoperative prediction of lymph node metastasis in endometrial carcinoma: a systematic review and meta-analysis. Oncologist 2019;24:e880-90.

97. Falcone F, Normanno N, Losito NS, Scognamiglio G, Esposito Abate R, Chicchinelli N, et al. Application of the Proactive Molecular Risk Classifier for Endometrial Cancer (ProMisE) to patients conservatively treated: outcomes from an institutional series. Eur J Obstet Gynecol Reprod Biol 2019;240:220-5.

98. Lee TY, Martinez-Outschoorn UE, Schilder RJ, Kim $\mathrm{CH}$, Richard SD, Rosenblum NG, et al. Metformin as a therapeutic target in endometrial cancers. Front Oncol 2018;8:341.

99. Kim MK, Seong SJ, Kang SB, Bae DS, Kim JW, Nam JH, et al. Six months response rate of combined oral medroxyprogesterone/levonorgestrel-intrauterine system for early-stage endometrial cancer in young women: a Korean Gynecologic-Oncology Group Study. J Gynecol Oncol 2019;30:e47.

100. Colombo N, Creutzberg C, Querleu D, Barahona M, Sessa C; ESMO Guidelines Committee. Appendix 5: endometrial cancer: eUpdate published online 8 June 2017 (www.esmo.org/Guidelines/GynaecologicalCancers). Ann Oncol 2017;28:iv153-6.

101. Yamagami W, Mikami M, Nagase S, Tabata T, Kobayashi $Y$, Kaneuchi $M$, et al. Japan Society of Gynecologic Oncology 2018 guidelines for treatment of uterine body neoplasms. J Gynecol Oncol 2020;31:e18.

102. Lee SW, Lee TS, Hong DG, No JH, Park DC, Bae JM, et al. Practice guidelines for management of uterine corpus cancer in Korea: a Korean Society of Gynecologic Oncology consensus statement. J Gynecol Oncol 2017;28:e12.

103. Kong TW, Ryu HS, Kim SC, Enomoto T, Li J, Kim KH, et al. Asian Society of Gynecologic Oncology International Workshop 2018. J Gynecol Oncol 2019;30:e39. 